\title{
Chemical composition of Piper sarmentosum extracts and antibacterial activity against the plant pathogenic bacteria Pseudomonas fuscovaginae and Xanthomonas oryzae pv. oryzae
}

\begin{abstract}
Piper sarmentosum is a cultivated plant that also growswildly in the South East Asian region. It is well known for its medicinal properties and a variety of active chemical constituents. The control potential of the plant extract against bacterial leaf blight caused by Xanthomonas oryzae andsheath brown rot of rice caused by Pseudomonas fuscovaginae wasevaluated. The aqueous methanol extracts of fruits and leaves of P. sarmentosum were chemically analyzed using gas-chromatography mass-spectrometry (GC-MS). The results gave the highest best matches of 28 compounds ( $80.2 \%$ of total extracts) in the leaf extract and 24 compounds (89.1\% of total extracts) in the fruit extract. The flavonoidfraction 4H-pyran-4-one,2,3dihydro-3,5-dihydroxy-6-methyl- (DDMP) was found to be the major component which constitutes a complex natural product that has been of recent medicinal interest. The extract of the fruit had IC50of 28.08 and $8.41 \mathrm{mg} \mathrm{ml}-1$ against P. fuscovaginae and X. oryzae, respectively, while the leaf extract had IC50of 10.42 and $24.69 \mathrm{mg} \mathrm{ml}-1$ against P. fuscovaginae and $\mathrm{X}$. oryzae, respectively.
\end{abstract}

Keyword: Antibacterial activity; Gas chromatography mass spectrometry (GC/MS); Inhibition concentration (IC); Methanol extracts; Rice pathogenic bacteria 